\title{
Analysis of Volatile Compounds in Coffee Prepared by Various Brewing and Roasting Methods
}

\author{
Ja-Myung Yu, Mingi Chu (D), Hyunbeen Park, Jooyeon Park and Kwang-Geun Lee *(D)
}

check for updates

Citation: Yu, J.-M.; Chu, M.; Park, H. Park, J.; Lee, K.-G. Analysis of Volatile Compounds in Coffee Prepared by Various Brewing and Roasting Methods. Foods 2021, 10, 1347. https://doi.org/10.3390/foods10061347

Academic Editor: Beatriz CanchoGrande

Received: 15 May 2021

Accepted: 9 June 2021

Published: 10 June 2021

Publisher's Note: MDPI stays neutral with regard to jurisdictional claims in published maps and institutional affiliations.

Copyright: (c) 2021 by the authors. Licensee MDPI, Basel, Switzerland. This article is an open access article distributed under the terms and conditions of the Creative Commons Attribution (CC BY) license (https:// creativecommons.org/licenses/by/ $4.0 /)$
Department of Food Science and Biotechnology, Dongguk University-Seoul, 32, Dongguk-ro, Ilsandong-gu, Goyang-si 10326, Korea; yujm91@hanmail.net (J.-M.Y.); alsrl0229@naver.com (M.C.); hbeen14@naver.com (H.P.); pjy041100@naver.com (J.P.)

* Correspondence: kwglee@dongguk.edu

\begin{abstract}
Volatile compounds of coffee brewed under various roasting conditions and by different brewing methods were analyzed. Green coffee beans (Coffea arabica) were roasted at $235{ }^{\circ} \mathrm{C}$ for $13 \mathrm{~min}, 240{ }^{\circ} \mathrm{C}$ for $15 \mathrm{~min}$, and $245^{\circ} \mathrm{C}$ for $17 \mathrm{~min}$. Roasted coffee beans were ground into particles of three different sizes $(710,500$, and $355 \mu \mathrm{m})$ and brewed by an espresso coffee machine and the cold brew method. Three types of water (filtered, tap, and bottled) were used for coffee extraction. SPME-GC-MS results indicated that increasing the roasting temperature and time increased the levels of $2,2^{\prime}$-methylene-bis-furan, guaiacol, and 4-ethylguaiacol $(p<0.05)$ and decreased the levels of furfural $(p<0.05)$. Grind size was inversely proportional to the measured signal of volatiles by GC-MS $(p<0.05)$. The measured GC/MS intensities of 2-methylpyrazine, 2,5-dimethylpyrazine, and 2-methoxy-4-vinylphenol were significantly higher in coffee brewed with filtered water $(p<0.05)$ than tap and bottled water. 2-Methylpyrazine, 1-methylpyrrole, and 2-acetylfuran were the most abundant components in the cold brew. Overall, roasting conditions and extraction methods were determined to be significant factors for volatile compounds in coffee. This is the first study showing the analysis of volatile compounds in coffee according to various types of water and extraction methods, such as espresso and cold brew coffee.
\end{abstract}

Keywords: volatiles; coffee; brewing; roasting; grinding

\section{Introduction}

Coffee is one of the most consumed beverages around the world. The conventional processing of coffee includes roasting, grinding, and extraction. During roasting, a wide range of chemical reactions occur, including the Maillard reaction, caramelization, and Strecker degradation [1]. These reactions affect not only the color of coffee but also the flavor and aroma [2-5]. Volatile flavor compounds in coffee are produced from a variety of compounds in green coffee beans, such as reducing sugars, amino acids, lipid, chlorogenic acid, and trigonelline [6].

The chemicals in coffee can be affected by various factors such as roasting conditions, ground particle size, and brewing methods. The grinding process is one of the most important steps for brewing coffee [7-9]. The particle size of ground coffee beans plays a significant role in controlling the degree of extraction via the particle's extraction kinetics $[10,11]$

Water (including its ionic composition) is an essential ingredient that can highlight the specificities of a coffee or leave it dull and flat [12]. The levels of ions and species in the water change the rate at which water is passed through the ground coffee [12]. It is well known that water treatment is required to remove possible off-flavors deriving from the disinfection (chlorination) process and to prevent limescale deposition associated with the water hardness [13].

Many brewing techniques may be used to prepare coffee [14,15]. Espresso is made by forcing hot water at high pressure (maximum of 19 bar) through finely ground coffee. 
This original Italian-style coffee is increasingly popular in many other countries [16,17]. Differences in flavor characteristics of espresso coffees as a result of the coffee variety and extraction temperature have been observed [18].

Cold brew coffee, which has been gaining popularity recently, is known to be smoother and sweeter than conventionally brewed coffee because the flavors and bioactive compounds in coffee are different from the hot water extraction method, such as expresso. Angeloni et al. reported that significant differences were found in the physicochemical parameters and sensory evaluation. Cold brew coffee was recognized as being less bitter with more contents of caffeine and chlorogenic compounds than expresso since higher temperature gives rise to an increase of solid compounds such as caffeine [19]. According to market research, the global cold brew market size was valued at USD 339.7 million in 2018 and is expected to reach USD 1.63 billion by 2025 [20]. Further, aside from its more appealing and less-acidic taste, cold brew coffee can contain up to two-fold more caffeine than hot brew coffee [21]. In addition, crude polysaccharides isolated from cold brew coffee serve as an inducer of the systemic immune system through the intestinal immune system [22]. Despite the growing popularity of cold brew coffee, there is little published on the chemistry or associated benefits or health risks of cold brew coffee.

Despite the growing popularity of cold brew coffee, there is little published on the chemistry or associated benefits or health risks of cold brew coffee. In this study, the volatile compounds produced in coffee under various roasting and brewing conditions, such as the grind size, types of water, and extraction methods, were analyzed and compared.

\section{Materials and Methods}

\subsection{Chemical Reagents and Materials}

Green coffee beans (Coffea arabica, from Brazil) were bought from a commercial market in Seoul, Korea. The origin of green coffee beans was verified by the importers and experts. 2-Methylpyrazine, 2,5-dimethylpyrazine, 2,6-dimethylpyrazine, 2-ethyl-3-methylpyrazine, 2ethyl-5-methylpyrazine, 3-ethyl-2,5-dimethylpyrazine, furfural, furfuryl acetate, furfuryl propionate, furfuryl alcohol, 1-furfurylpyrrole, 4-ethylguaiacol, 2-methoxy-4-vinylphenol, 5methylfurfural, quinoxaline, and C7-C30 alkane standard were obtained from Sigma-Aldrich Chemical Co. (St. Louis, MO, USA). 2-Ethylpyrazine, 2,3-dimethylpyrazine, 1-methylpyrrole, guaiacol, and 2-acetylfuran were bought from Tokyo Chemical Industry Co., Ltd. (Tokyo, Japan). Divinylbenzene/carboxen/polydimethylsiloxane (DVB/CAR/PDMS, 50- $\mu \mathrm{m}$ film thickness) solid-phase microextraction (SPME) fiber was purchased from Supelco, Inc. (Bellefonte, PA, USA).

\subsection{Sample Preparation}

Green coffee beans were roasted under three different conditions $\left(235^{\circ} \mathrm{C}\right.$ for $13 \mathrm{~min}$, $240{ }^{\circ} \mathrm{C}$ for $15 \mathrm{~min}$, and $245^{\circ} \mathrm{C}$ for $17 \mathrm{~min}$ ) in a coffee bean roaster (CBR-101A, Gene Café, Korea). Each roasted bean was ground in a grinder (Hanil, Seoul, Korea) for $30 \mathrm{~s}$ twice. These samples passed through testing sieves $(710,500$, and $355 \mu \mathrm{m})$ for 2 min twice in a sieve shaker. Two different extraction methods (expresso and cold brew) were then applied. For espresso coffee, roasted ground coffee $(12.5 \mathrm{~g})$ was brewed with $100 \mathrm{~mL}$ of water using an espresso coffee machine (BCC-480ES, Bean Cruise, Korea). Cold brew coffee was made based on the New York Times' cooking website. A sample of $12.5 \mathrm{~g}$ was placed in $100 \mathrm{~mL}$ of water at room temperature for $4 \mathrm{~h}$, and then at $4{ }^{\circ} \mathrm{C}$ for $8 \mathrm{~h}$ [21]. Three types of water (filtered, tap, and bottled water) were used for coffee extraction.

In total, fifty-four coffee samples were prepared, and the sample names were abbreviated from E-1 to E-27 (extraction method), and from C-1 to C-27 (cold brew). According to the roasting conditions, sample numbers were divided into 1 to $9\left(235^{\circ} \mathrm{C}\right.$ for $\left.13 \mathrm{~min}\right)$, $10-18\left(240{ }^{\circ} \mathrm{C}\right.$ for $\left.15 \mathrm{~min}\right)$, and $19-27\left(245^{\circ} \mathrm{C}\right.$ for $\left.17 \mathrm{~min}\right)$. The sample number was also assigned to the particle size of grounded coffee (355 $\mu \mathrm{m}: 1-3,10-12,19-21 ; 500 \mu \mathrm{m}: 4-6$, 13-15, 22-24; $710 \mu \mathrm{m}: 7-9,16-18,25-27)$. The sample number assigned according to the size of the coffee bean was divided into three equal parts according to the type of water (fil- 
tered water: 1, 4, 7, 10, 13, 16, 19, 22, 25; tap water: 2, 5, 8, 11, 14, 17, 20, 23, 26; bottled water: $3,6,9,12,15,18,21,24,27)$.

\subsection{Analysis of Volatile Compounds}

Volatile compounds in coffee were extracted using SPME. A $10 \mathrm{~mL}$ of sample was added to the GC vial. The internal standard quinoxaline $(10 \mu \mathrm{L})$, the alkane standard $(20 \mu \mathrm{L})$, and a magnetic stirring bar were added. After stirring the samples at $70{ }^{\circ} \mathrm{C}$ for $10 \mathrm{~min}$, to reach equilibrium, the SPME fiber was injected into the vial at $70^{\circ} \mathrm{C}$ for $40 \mathrm{~min}$ for adsorption of volatile compounds. Afterward, the fiber was inserted into the gas chromatograph. Gas chromatography-mass spectrometry (GC-MS) analysis was performed using a DB-WAX column (length $\times$ inside diameter $\times$ phase thickness: $60 \mathrm{~m} \times 250 \mu \mathrm{m} \times 0.25 \mu \mathrm{m}$ ) by modifying an existing method [6]. Helium was used as the carrier gas, with a flow rate of $1.0 \mathrm{~mL} / \mathrm{min}$ and splitless mode (splitless time: $1 \mathrm{~min}$ ). The oven temperature was maintained at $44^{\circ} \mathrm{C}$ for $5 \mathrm{~min}$, increased to $170{ }^{\circ} \mathrm{C}$ at $3^{\circ} \mathrm{C} / \mathrm{min}$ and held for $10 \mathrm{~min}$, and then raised to $240{ }^{\circ} \mathrm{C}$ at $8{ }^{\circ} \mathrm{C} / \mathrm{min}$ and held for $5 \mathrm{~min}$. Volatile compounds were identified by their retention index (RI), co-injection, and by comparison of their mass spectra with those published in the Wiley mass spectrum database. The peak area ratio (peak area of each peak/peak area of internal standard) of each compound was calculated from the peak area of the internal standard. All analyses were conducted in three replications, and average value and standard deviations were calculated.

\subsection{Statistical Analysis}

Statistical analysis was performed with IBM SPSS Statistics 23 (IBM, Armonk, NY, USA), and graphs were constructed with GraphPad Prism 5.0 software (GraphPad Software, Inc., San Diego, CA, USA). All data were analyzed by one-way ANOVA and Duncan's multiple range test for investigating significant differences $(p<0.05)$. Principal component analysis (PCA) was performed on the mean values of peak area ratio using XLSTAT (version 2018; Addinsoft, Paris, France).

\section{Results}

\subsection{Analysis of Volatile Compounds in Coffee}

The selected 24 volatile compounds are shown in Table 1 . These selected volatile compounds are the main volatiles identified in coffee samples. In addition, these 24 volatiles were analyzed the most in our study and represent the aroma's functional groups (chemical types) in coffee. Identification of the volatile compounds was based on their RI, co-injection, and comparison of their mass spectrum with those in the Wiley mass spectrum database. All values are represented as the peak area ratio (peak area of each peak/peak area of internal standard). Table 2 shows the peak area ratio of the volatile compounds in E-1 to E-9 (espresso roasted at $235^{\circ} \mathrm{C}$ for $13 \mathrm{~min}$ ) and C- 1 to C-9 (cold brew roasted at $235^{\circ} \mathrm{C}$ for $13 \mathrm{~min})$. Among the espresso coffees, the finest grinds $(355 \mu \mathrm{m})$ produced significantly higher measured GC/MS intensities of all 24 volatile compounds, except for 2,2'-[oxybis (methylene)]bis-furan and 2-methoxy-4-vinylphenol, compared with the medium (500 $\mu \mathrm{m})$ and large $(750 \mu \mathrm{m})$ grind sizes $(p<0.05)$. For espresso coffees extracted with different types of water, bottled water and tap water led to high measured GC/MS intensities of all 24 volatile compounds. Comparing cold brew coffees, fine grinds $(355 \mu \mathrm{m})$ resulted in significantly high measured GC/MS intensities of volatile compounds, respectively $(p<0.05)$.

For cold brew coffees (C-1 to C-9), filtered water led to significantly higher measured GC/MS intensities of volatile compounds $(p<0.05)$. The water used in this study has different amounts of carbonates and bicarbonates. The levels of carbonates and bicarbonate were much lower in the filtered water compared to the bottled and tap water. A study by Gardner (1958) showed that the carbonates and bicarbonates of sodium ions slowed down the brewing time. Therefore, cold brew, which is extracted by soaking coffee beans in water, 
appears to have been more affected by the extraction of volatile compounds than espresso coffee [12].

Table 3 shows the volatile compounds in both types of coffee roasted at $240{ }^{\circ} \mathrm{C}$ for $15 \mathrm{~min}$. Among the espresso coffees (E-10 to E-18), the smaller particle of ground coffee $(355 \mu \mathrm{m})$ corresponded to significantly higher measured GC/MS intensities of volatile compounds $(p<0.05)$. Among the espresso coffees extracted with different types of water (E-10, E-11, and E-12), filtered water resulted in significantly higher measured GC/MS intensities of 18 volatile compounds $(p<0.05)$. Comparing E-13, E-14, and E-15, the measured GC/MS intensities of 22 volatile compounds, excluding 2-methylpyrazine and furfuryl alcohol, were notably high when filtered water was used $(p<0.05)$. Comparing E-16, E-17, and E-18, tap water led to significantly higher measured GC/MS intensities of 21 volatile compounds $(p<0.05)$. Comparing cold brew samples, fine grinds $(355 \mu \mathrm{m})$ occasioned notably high levels of volatile compounds, respectively $(p<0.05)$. Among C-10 to C-12, the measured GC/MS intensities of all 24 volatile compounds were similarly detected. Among C-13 to $\mathrm{C}-15$ and $\mathrm{C}-16$ to $\mathrm{C}-18$, filtered water gave rise to remarkably high measured GC/MS intensities of 19 and 2 volatile compounds, respectively $(p<0.05)$. For extraction with filtered water, more volatiles could be expected to be detected as grind size decreases and roasting temperature increases. However, in this study, espresso prepared from filtered water and at a relatively low roasting temperature did not generate a high concentration of volatiles. Similarly, cold brew prepared from fine grinds and filtered water did not have a high concentration of volatiles. The reason for this result should be examined in future studies.

Table 1. Volatile compounds in coffee (E-1: espresso brewing method, roasted at $235^{\circ} \mathrm{C}$ for 13 min, particle size of ground coffee bean $355 \mu \mathrm{m}$, and purified water).

\begin{tabular}{|c|c|c|c|c|c|c|}
\hline No. & Compounds & Retention Time & R.I & R.I (Ref) & $\begin{array}{c}\text { Co- } \\
\text { Injection }\end{array}$ & Mass Spectrum \\
\hline a1 & 2-Methylpyrazine & 25.99 & 1289 & 1288 & $\mathrm{o}$ & o \\
\hline $\mathrm{a} 2$ & 2,3-Dimethylpyrazine & 29.87 & 1370 & 1371 & $\mathrm{o}$ & o \\
\hline a3 & 2,5-Dimethylpyrazine & 28.73 & 1346 & 1348 & $\mathrm{o}$ & o \\
\hline $\mathrm{a} 4$ & 2,6-Dimethylpyrazine & 29.02 & 1352 & 1354 & $\mathrm{o}$ & o \\
\hline a5 & 2-Ethylpyrazine & 29.23 & 1356 & 1359 & $\mathrm{o}$ & o \\
\hline a6 & 2,6-Diethylpyrazine & 33.83 & 1456 & 1444 & & o \\
\hline a7 & 2-Ethyl-3-methylpyrazine & 32.54 & 1427 & 1422 & o & $\mathrm{o}$ \\
\hline a8 & 2-Ethyl-5-methylpyrazine & 31.64 & 1407 & 1415 & & o \\
\hline a9 & 3-Ethyl-2,5-dimethylpyrazine & 34.32 & 1467 & 1452 & o & o \\
\hline a10 & Isopropenyl pyrazine & 40.82 & 1619 & & & o \\
\hline b1 & 2-Acetylfuran & 36.74 & 1522 & 1527 & $\mathrm{o}$ & $\mathrm{o}$ \\
\hline $\mathrm{b} 2$ & 2,2'-Bifuran & 40.47 & 1610 & 1614 & & $\mathrm{o}$ \\
\hline b3 & 2,2'-Methylenebisfuran & 40.93 & 1622 & 1615 & & $\mathrm{o}$ \\
\hline $\mathrm{b} 4$ & $\begin{array}{c}2,2^{\prime}- \\
\text { [Oxybis(methylene)]bisfuran }\end{array}$ & 57.71 & 1997 & 1986 & & $\mathrm{o}$ \\
\hline b5 & Furfuryl alcohol & 42.84 & 1669 & 1666 & $\mathrm{o}$ & $\mathrm{o}$ \\
\hline b6 & Furfuryl acetate & 37.82 & 1547 & 1552 & $\mathrm{o}$ & $\mathrm{o}$ \\
\hline b7 & Furfuryl propionate & 40.36 & 1607 & 1603 & $\mathrm{o}$ & o \\
\hline b8 & Furfural & 34.81 & 1477 & 1482 & $\mathrm{o}$ & $\mathrm{o}$ \\
\hline b9 & 5-Methylfurfural & 39.63 & 1590 & 1596 & o & o \\
\hline c1 & 1-Methylpyrrole & 19.30 & 1147 & 1140 & o & o \\
\hline c2 & 1-Furfurylpyrrole & 49.66 & 1841 & 1833 & $\mathrm{o}$ & $\mathrm{o}$ \\
\hline $\mathrm{d} 1$ & Guaiacol (2-Methoxyphenol) & 51.10 & 1874 & 1872 & o & o \\
\hline $\mathrm{d} 2$ & 4-Ethylguaiacol & 59.93 & 2052 & 2054 & $\mathrm{o}$ & $\mathrm{o}$ \\
\hline $\mathrm{d} 3$ & 2-Methoxy-4-vinylphenol & 64.80 & & 2156 & $\mathrm{o}$ & $\mathrm{o}$ \\
\hline
\end{tabular}

Identification for volatile compounds compared with Retention Index (RI) on DB-WAX column in NIST and VCF library, co-injection, and mass spectrum. 
Table 4 lists the volatile compounds in both types of coffee roasted at $245^{\circ} \mathrm{C}$ for $17 \mathrm{~min}$ (E-19 to E-27 and C-19 to C-27). Comparing expresso coffee samples, fine grinds (355 $\mu \mathrm{m})$ led to significantly high measured GC/MS intensities of volatile compounds, respectively $(p<0.05)$. Among E-19 to E-21, filtered water led to slightly but not significantly high measured GC/MS intensities of all 24 volatile compounds $(p>0.05)$, except for isopropenyl pyrazine, 2,6-diethylpyrazine, and 2-methoxy-4-vinylphenol. Among E-22 to E-24 and E-25 to E-27, filtered water resulted in significantly high measured GC/MS intensities of 6 and 18 volatile compounds, respectively $(p<0.05)$. Comparing cold brew samples, there were no or highly significant differences in grind sizes 500 and $710 \mu \mathrm{m}$. Filtered water occasioned significantly high measured GC/MS intensities of 1-furfurylpyrrole and 2methoxy-4-vinylphenol among cold brews C-19 to C-21 $(p<0.05)$, furfuryl alcohol among cold brews C-22 to C-24 ( $p<0.05)$, and 12 volatile compounds among cold brews C-25 to C-27 ( $p<0.05)$. Comparing volatile compounds of middle size $(500 \mu \mathrm{m})$ of ground coffee, the levels of 2-methylpyrazine, 2,5-Dimethylpyrazine, 2,6-Dimethylpyrazine, 2ethylpyrazine, 2-ethyl-5-methylpyrazine, 3-ethyl-2,5-dimethylpyrazine, 2-acetylfuran, 2,2' Bifuran, 5-Methylfurfural, and 1-methylpyrrole in cold brew coffee were higher than espresso coffee. These flavor compounds have a sweet, nutty, and fruity odor [23-26].

In Figure 1, among the many volatile compounds analyzed, significantly increased or decreased compounds were selected to show their levels. As shown in Figure 1a, increasing the roasting temperature and time increased the levels of 2,2'-methylene-bisfuran, guaiacol, and 4-ethylguaiacol $(p<0.05)$, and decreased the levels of furfural and 5 -methylfurfural $(p<0.05)$. In Moon and Shibamoto's (2009) study, intensifying the roasting conditions of green coffee beans yielded relatively lower furanone derivatives and furfural. This result is possibly associated with the interconversion of furan, furfural, furfuryl alcohol, and 2-methylfuran. In particular, the high activation energy of furfural reduction to furan is shown to be thermodynamically favored [27]. In addition, the formation of aroma compounds, such as pyrroles, generated by the Maillard reaction between reducing sugars and amino acids, were formed more in coffee beans roasted under higher roasting conditions than mild roasting conditions [3].

As shown in Figure 1b, the smaller the grind size, the higher the measured GC/MS intensities of 2-ethyl-5-methylpyrazine, 4-ethylguaiacol, and 2-acetylfuran $(p<0.05)$. As the grind size decreases, the solid-liquid interfacial area increases, in turn, increasing the levels of volatile compounds extracted [11]. Other studies reported that coffee prepared with rough coffee grounds had the lowest aromatic profile [16,28]. Trigonelline, chlorogenic acids, and lipids increased inversely with grind size. The caffeine content also increased significantly as grind size decreased $[18,29]$. These results suggest that different aromatic profiles of coffee can be obtained when different grind sizes are used. As the size of the particles decreases, the packing effect becomes higher, and the perfusion of the water in coffee samples becomes difficult. Therefore, the particle size is usually optimized according to the type of extraction methods, such as the machine used for the preparation of the coffee. In a future study, the optimization of coffee machines could be carried out.

In Figure 1c, high measured GC/MS intensities of 2-methylpyrazine, 2,5-dimethylpyrazine, and 2-methoxy-4-vinylphenol were observed in coffee brewed with filtered water than bottled water. Water quality can have a direct impact on the quality of espresso coffee. Brewed coffees often differed in flavor and appearance, depending on whether the water was distilled, soft, or hard. Beverages made with solutions containing carbonates were the least desirable, having a flat and dull characteristic [12]. 


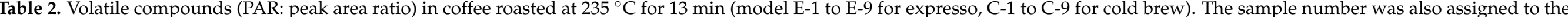

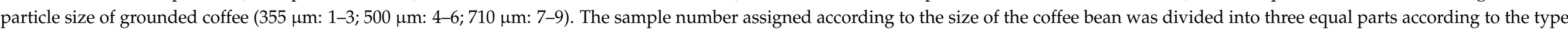
of water (filtered water: 1, 4, 7; tap water: 2, 5, 8; bottled water: 3, 6, 9).

\begin{tabular}{|c|c|c|c|c|c|c|c|c|c|c|c|c|c|c|c|c|c|c|}
\hline \multirow{4}{*}{ Compounds } & \multicolumn{18}{|c|}{$235^{\circ} \mathrm{C}, 13 \mathrm{~min}$} \\
\hline & \multicolumn{6}{|c|}{$355 \mu \mathrm{m}$} & \multicolumn{6}{|c|}{$500 \mu \mathrm{m}$} & \multicolumn{6}{|c|}{$710 \mu \mathrm{m}$} \\
\hline & \multicolumn{2}{|c|}{ Filtered Water } & \multicolumn{2}{|c|}{ Tap Water } & \multicolumn{2}{|c|}{ Bottled Water } & \multicolumn{2}{|c|}{ Filtered Water } & \multicolumn{2}{|c|}{ Tap Water } & \multicolumn{2}{|c|}{ Bottled Water } & \multicolumn{2}{|c|}{ Filtered Water } & \multicolumn{2}{|c|}{ Tap Water } & \multicolumn{2}{|c|}{ Bottled Water } \\
\hline & E-1 & C-1 & E-2 & $\mathrm{C}-2$ & E-3 & C-3 & E-4 & C-4 & E-5 & C-5 & E-6 & C-6 & E-7 & C-7 & E-8 & C-8 & E-9 & C-9 \\
\hline 2-Methylpyrazine & $0.382^{\mathrm{b}}$ & $0.885^{\mathrm{a}}$ & $0.941^{\mathrm{a}}$ & $0.615^{\mathrm{b}}$ & $0.852^{a}$ & $0.596^{\mathrm{b}}$ & 0.338 & $0.641^{\mathrm{a}}$ & 0.288 & $0.505^{\mathrm{b}}$ & 0.324 & $0.520^{\mathrm{b}}$ & $0.190^{b}$ & $0.605^{\mathrm{a}}$ & $0.436^{\mathrm{a}}$ & $0.591^{\mathrm{a}}$ & $0.186^{\mathrm{b}}$ & $0.493^{b}$ \\
\hline 2,3-Dimethylpyrazine & $0.048^{\mathrm{b}}$ & $0.070^{\mathrm{b}}$ & $0.068^{\mathrm{ab}}$ & $0.087^{a b}$ & $0.056^{\mathrm{a}}$ & $0.098^{\mathrm{a}}$ & 0.040 & $0.097^{\mathrm{a}}$ & 0.031 & $0.075^{\mathrm{b}}$ & 0.041 & $0.056^{\mathrm{c}}$ & $0.019^{\mathrm{b}}$ & $0.056^{\mathrm{a}}$ & $0.032^{\mathrm{a}}$ & $0.046^{\mathrm{b}}$ & $0.022^{\mathrm{b}}$ & $0.039^{\mathrm{b}}$ \\
\hline 2,5-Dimethylpyrazine & $0.237^{b}$ & $0.523^{\mathrm{a}}$ & $0.553^{\mathrm{a}}$ & $0.371^{\mathrm{b}}$ & $0.518^{\mathrm{a}}$ & $0.346^{\mathrm{b}}$ & 0.213 & $0.383^{\mathrm{a}}$ & 0.188 & $0.304^{\mathrm{b}}$ & 0.205 & $0.302^{\mathrm{b}}$ & $0.104^{b}$ & $0.352^{\mathrm{a}}$ & $0.224^{\mathrm{a}}$ & $0.340^{\mathrm{a}}$ & $0.102^{\mathrm{b}}$ & $0.269^{\mathrm{b}}$ \\
\hline 2,6-Dimethylpyrazine & $0.215^{\mathrm{b}}$ & $0.438^{\mathrm{a}}$ & $0.451^{\mathrm{a}}$ & $0.292^{\mathrm{b}}$ & $0.435^{\mathrm{a}}$ & $0.298^{\mathrm{b}}$ & 0.184 & 0.302 & 0.164 & 0.245 & 0.182 & 0.253 & $0.090^{\mathrm{b}}$ & $0.279^{\mathrm{a}}$ & $0.187^{\mathrm{a}}$ & $0.266^{a b}$ & $0.093^{\mathrm{b}}$ & $0.213^{\mathrm{b}}$ \\
\hline 2-Ethylpyrazine & $0.189^{b}$ & $0.338^{\mathrm{a}}$ & $0.372^{\mathrm{a}}$ & $0.252^{\mathrm{b}}$ & $0.366^{\mathrm{a}}$ & $0.243^{\mathrm{b}}$ & 0.161 & $0.258^{\mathrm{a}}$ & 0.143 & $0.197^{\mathrm{b}}$ & 0.153 & $0.206^{\mathrm{b}}$ & $0.072^{\mathrm{b}}$ & 0.218 & $0.148^{\mathrm{a}}$ & 0.209 & $0.074^{\mathrm{b}}$ & 0.174 \\
\hline 2,6-Diethylpyrazine & $0.082^{b}$ & 0.219 & $0.100^{a b}$ & 0.213 & $0.125^{\mathrm{a}}$ & 0.209 & 0.057 & $0.199^{\mathrm{a}}$ & 0.052 & $0.163^{\mathrm{b}}$ & 0.061 & $0.172^{\mathrm{a}}$ & 0.032 & $0.114^{\mathrm{a}}$ & 0.035 & $0.104^{\mathrm{a}}$ & 0.044 & $0.079^{\mathrm{b}}$ \\
\hline $\begin{array}{c}\text { 2-Ethyl- } \\
\text { 3-methylpyrazine }\end{array}$ & $0.247^{\mathrm{b}}$ & 0.402 & $0.489^{\mathrm{a}}$ & 0.312 & $0.482^{\mathrm{a}}$ & 0.316 & 0.211 & $0.312^{\mathrm{a}}$ & 0.196 & $0.245^{\mathrm{b}}$ & 0.219 & $0.263^{\mathrm{b}}$ & $0.096^{\mathrm{b}}$ & $0.297^{\mathrm{a}}$ & $0.189^{\mathrm{a}}$ & $0.297^{\mathrm{a}}$ & $0.099^{b}$ & $0.231^{b}$ \\
\hline $\begin{array}{l}\text { 2-Ethyl- } \\
\text { 5-methylpyrazine }\end{array}$ & $0.317^{\mathrm{b}}$ & $0.326^{\mathrm{a}}$ & $0.384^{\mathrm{ab}}$ & $0.256^{\mathrm{b}}$ & $0.393^{\mathrm{a}}$ & $0.278^{a b}$ & 0.262 & 0.259 & 0.213 & 0.217 & 0.225 & 0.217 & 0.104 & $0.237^{\mathrm{ab}}$ & 0.141 & $0.257^{\mathrm{a}}$ & 0.140 & $0.205^{\mathrm{b}}$ \\
\hline $\begin{array}{l}\text { 3-Ethyl- } \\
\text { 2,5-imethylpyrazine }\end{array}$ & $0.422^{b}$ & $0.753^{\mathrm{a}}$ & $1.059^{\mathrm{a}}$ & $0.587^{b}$ & $1.027^{\mathrm{a}}$ & $0.613^{\mathrm{ab}}$ & $0.336^{\mathrm{a}}$ & 0.588 & $0.297^{b}$ & 0.491 & $0.347^{\mathrm{a}}$ & 0.522 & $0.139^{\mathrm{b}}$ & $0.500^{\mathrm{a}}$ & $0.398^{\mathrm{a}}$ & $0.462^{\mathrm{a}}$ & $0.145^{\mathrm{b}}$ & $0.399^{b}$ \\
\hline Isopropenyl pyrazine & $0.048^{\mathrm{b}}$ & 0.104 & $0.120^{\mathrm{a}}$ & 0.100 & $0.115^{\mathrm{a}}$ & 0.100 & 0.043 & 0.098 & 0.047 & 0.093 & 0.052 & 0.098 & $0.026^{\mathrm{b}}$ & $0.106^{\mathrm{a}}$ & $0.038^{\mathrm{a}}$ & $0.105^{\mathrm{a}}$ & $0.019^{\mathrm{b}}$ & $0.082^{b}$ \\
\hline 2-Acetylfuran & $0.308^{\mathrm{b}}$ & $0.738^{\mathrm{a}}$ & $0.643^{\mathrm{a}}$ & $0.551^{\mathrm{b}}$ & $0.632^{\mathrm{a}}$ & $0.541^{\mathrm{b}}$ & 0.239 & 0.475 & 0.229 & 0.380 & 0.264 & 0.392 & $0.133^{\mathrm{b}}$ & $0.382^{\mathrm{a}}$ & $0.238^{\mathrm{a}}$ & 0.354 ab & $0.147^{\mathrm{b}}$ & $0.260^{\mathrm{b}}$ \\
\hline $2,2^{\prime}$-Bifuran & $0.086^{\mathrm{b}}$ & 0.088 & $0.267^{\mathrm{a}}$ & 0.092 & $0.222^{\mathrm{a}}$ & 0.092 & 0.069 ab & $0.077^{\mathrm{a}}$ & $0.062^{\mathrm{b}}$ & $0.060^{\mathrm{b}}$ & $0.077^{\mathrm{a}}$ & $0.067^{\mathrm{ab}}$ & $0.045^{\mathrm{b}}$ & $0.056^{\mathrm{ab}}$ & $0.127^{a}$ & $0.062^{a}$ & $0.061^{\mathrm{b}}$ & $0.045^{\mathrm{b}}$ \\
\hline 2,2'-Methylenebisfuran & $0.078^{\mathrm{b}}$ & 0.086 & $0.225^{\mathrm{a}}$ & 0.086 & $0.193^{\text {a }}$ & 0.092 & $0.072^{\mathrm{b}}$ & 0.052 & $0.071^{\mathrm{b}}$ & 0.043 & $0.081^{\mathrm{a}}$ & 0.046 & $0.047^{\mathrm{b}}$ & $0.041^{\mathrm{a}}$ & $0.103^{\text {a }}$ & $0.041^{\mathrm{a}}$ & $0.054^{\mathrm{b}}$ & $0.031^{\mathrm{b}}$ \\
\hline $\begin{array}{c}\text { 2,2'-[Oxybis } \\
\text { (methylene)]bisfuran }\end{array}$ & $0.124^{\mathrm{b}}$ & 0.235 & $0.591^{\mathrm{a}}$ & 0.238 & $0.612^{\mathrm{a}}$ & 0.259 & $0.117^{\mathrm{a}}$ & $0.811^{\mathrm{b}}$ & $0.087^{\mathrm{b}}$ & $0.964^{\mathrm{ab}}$ & $0.112^{\mathrm{ab}}$ & $1.063^{\mathrm{a}}$ & $0.081^{\mathrm{c}}$ & 0.247 & $0.244^{\mathrm{a}}$ & 0.226 & $0.154^{\mathrm{b}}$ & 0.215 \\
\hline 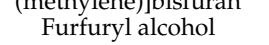 & $1.656^{\mathrm{b}}$ & $2.758^{\mathrm{a}}$ & $2.710^{\mathrm{a}}$ & $1.967^{\mathrm{b}}$ & $2.514^{\mathrm{a}}$ & $1.813^{\mathrm{b}}$ & 1.405 & $1.729^{\mathrm{ab}}$ & 1.335 & $1.495^{\mathrm{b}}$ & 1.355 & $1.788^{\mathrm{a}}$ & $0.728^{\mathrm{b}}$ & 1.479 & $1.379^{\mathrm{a}}$ & 1.553 & $0.768^{\mathrm{b}}$ & 1.349 \\
\hline Furfuryl acetate & $0.891^{\mathrm{b}}$ & 1.916 & $2.194^{\mathrm{a}}$ & 1.545 & $2.321^{\mathrm{a}}$ & 1.532 & $0.706^{\mathrm{ab}}$ & $1.190^{\mathrm{a}}$ & $0.636^{\mathrm{b}}$ & $0.832^{\mathrm{b}}$ & $0.731^{\mathrm{a}}$ & $0.937^{b}$ & $0.289^{\mathrm{b}}$ & 0.749 & $0.715^{\text {a }}$ & 0.775 & $0.332^{\mathrm{b}}$ & 0.627 \\
\hline Furfuryl propionate & $0.058^{\mathrm{b}}$ & 0.103 & $0.091^{\mathrm{a}}$ & 0.083 & $0.103^{\mathrm{a}}$ & 0.084 & $0.043^{\mathrm{ab}}$ & 0.055 & $0.039^{\mathrm{b}}$ & 0.045 & $0.050^{\mathrm{a}}$ & 0.045 & $0.013^{\mathrm{b}}$ & $0.037^{\mathrm{a}}$ & $0.033^{\mathrm{a}}$ & $0.036^{\mathrm{a}}$ & $0.010^{\mathrm{b}}$ & $0.028^{\mathrm{b}}$ \\
\hline 1-Methylpyrrole & $0.076^{\mathrm{b}}$ & 0.167 & $0.114^{\mathrm{a}}$ & 0.134 & $0.147^{\mathrm{a}}$ & 0.128 & 0.055 & $0.156^{\mathrm{a}}$ & 0.056 & $0.113^{b}$ & 0.064 & $0.121^{\mathrm{b}}$ & $0.024^{\mathrm{b}}$ & $0.133^{a b}$ & $0.075^{\mathrm{a}}$ & $0.140^{\mathrm{a}}$ & $0.025^{\mathrm{b}}$ & $0.103^{b}$ \\
\hline 1-Furfurylpyrrole & $1.548^{\mathrm{a}}$ & $0.761^{\mathrm{a}}$ & $1.204^{\mathrm{b}}$ & $0.612^{\mathrm{b}}$ & $1.087^{\mathrm{b}}$ & $0.643^{\mathrm{ab}}$ & 1.062 & 0.565 & 1.210 & 0.471 & 1.258 & 0.495 & 0.599 & 0.395 & 0.490 & 0.401 & 0.510 & 0.357 \\
\hline Guaiacol & $0.108^{\mathrm{b}}$ & $0.352^{\mathrm{a}}$ & $0.184^{\text {a }}$ & $0.248^{\mathrm{b}}$ & $0.165^{\mathrm{a}}$ & $0.249^{\mathrm{b}}$ & 0.090 & 0.257 & 0.083 & 0.232 & 0.089 & 0.229 & 0.055 & 0.055 & 0.064 & 0.051 & 0.056 & 0.045 \\
\hline 4-Ethylguaiacol & $0.337^{\mathrm{b}}$ & 0.366 & $0.976^{\mathrm{a}}$ & 0.336 & $0.944^{\mathrm{a}}$ & 0.357 & 0.334 & $0.242^{\mathrm{b}}$ & 0.321 & $0.242^{\mathrm{b}}$ & 0.344 & $0.340^{\mathrm{a}}$ & $0.190^{\mathrm{b}}$ & 0.444 & $0.404^{\mathrm{a}}$ & 0.456 & $0.168^{\mathrm{b}}$ & 0.429 \\
\hline $\begin{array}{l}\text { 2-Methoxy- } \\
\text { 4-vinylphenol }\end{array}$ & $3.612^{\mathrm{a}}$ & 1.367 & $2.937^{b}$ & 1.388 & $2.851^{b}$ & 1.412 & $3.253^{b}$ & $1.520^{\mathrm{b}}$ & $3.348^{\mathrm{b}}$ & $1.576^{\mathrm{b}}$ & $3.735^{\mathrm{a}}$ & $1.727^{\mathrm{a}}$ & $1.647^{\mathrm{a}}$ & $1.311^{\mathrm{b}}$ & $1.469^{\mathrm{b}}$ & $1.431^{\mathrm{a}}$ & $1.286^{c}$ & $1.477^{\mathrm{a}}$ \\
\hline
\end{tabular}

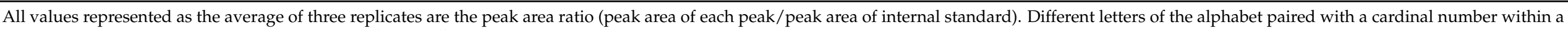
particle size and extraction method indicate significant differences in the type of water according to Duncan's test between each sample $(p<0.05)$. 


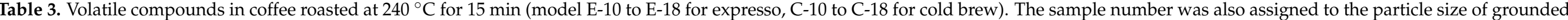

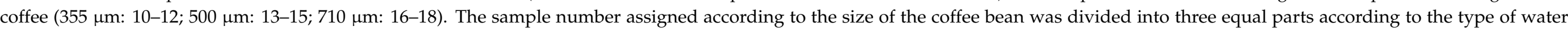
(filtered water: 10, 13, 16; tap water: 11, 14, 17; bottled water: 12, 15, 18).

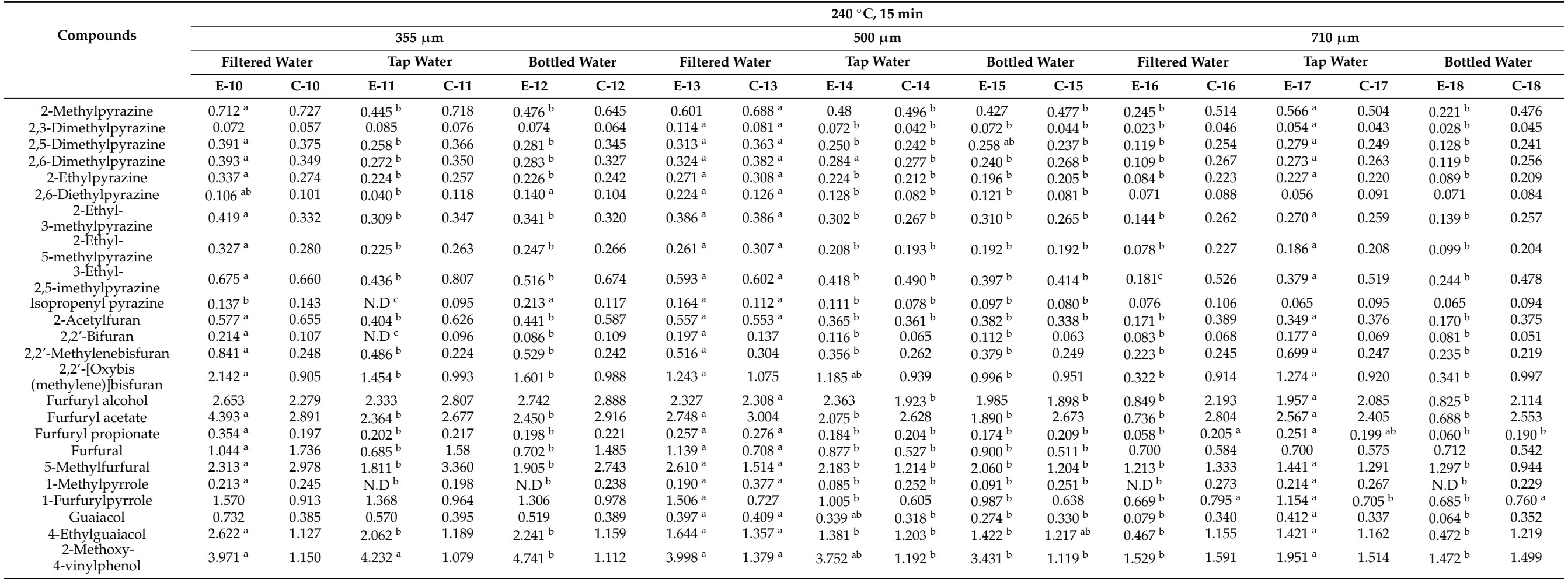

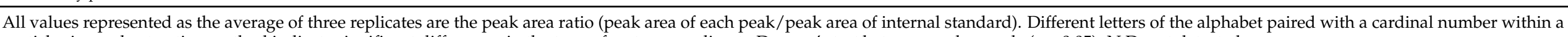
particle size and extraction method indicate significant differences in the type of water according to Duncan's test between each sample $(p<0.05)$. N.D: not detected. 


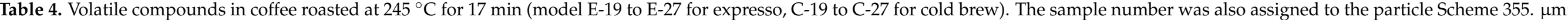

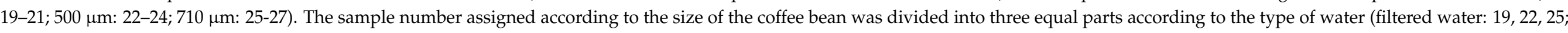
tap water: 20, 23, 26; bottled water: 21, 24, 27).

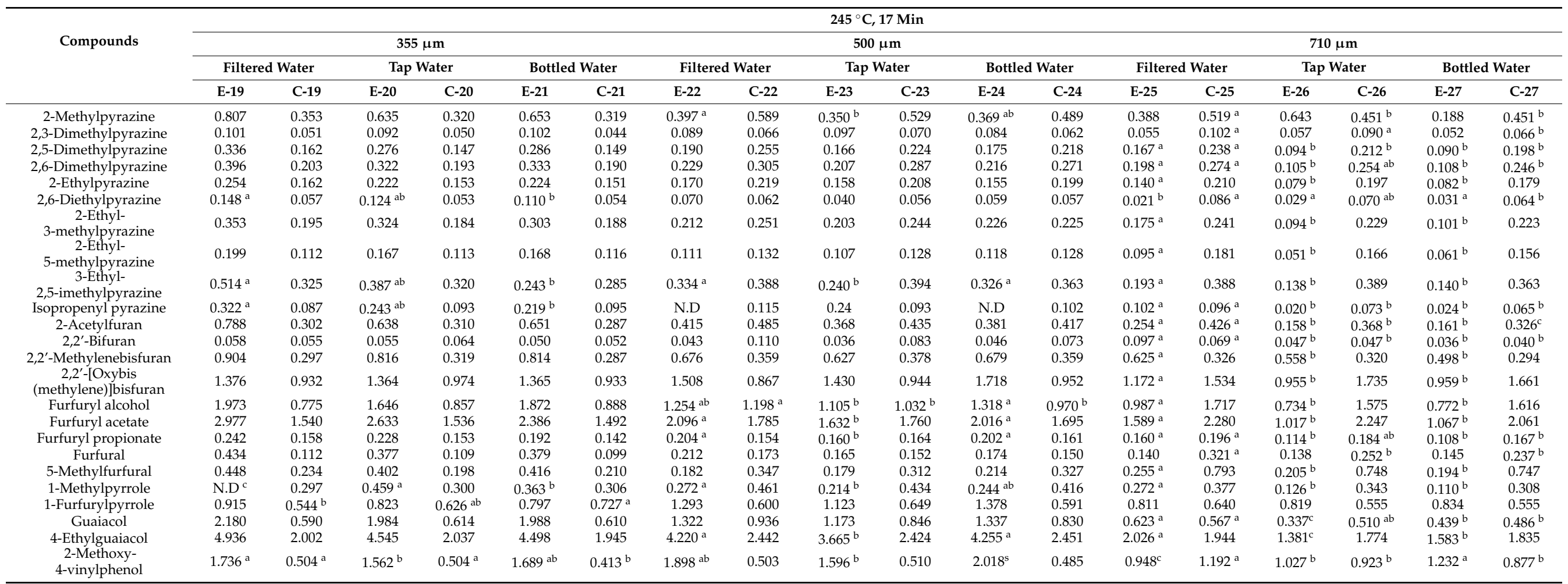

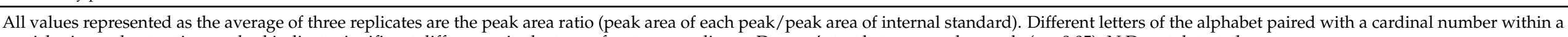
particle size and extraction method indicate significant differences in the type of water according to Duncan's test between each sample $(p<0.05)$. N.D: not detected. 


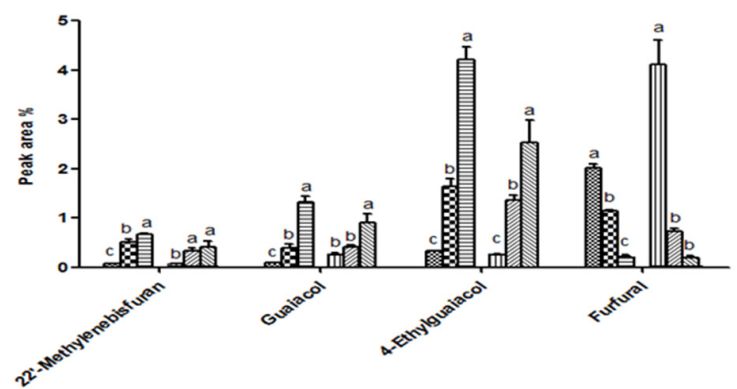

(a)

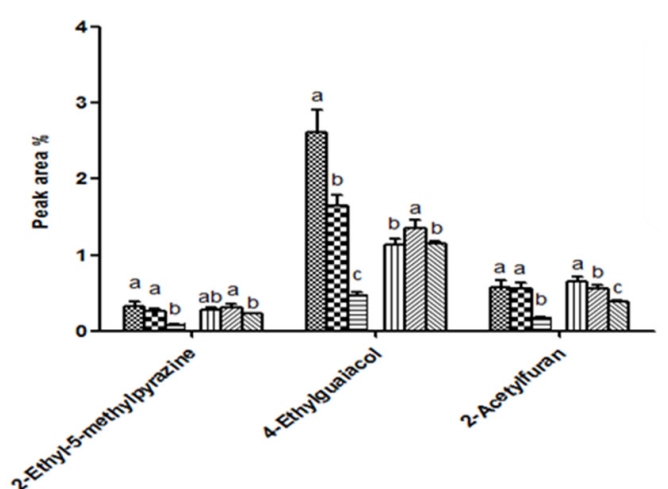

(b)

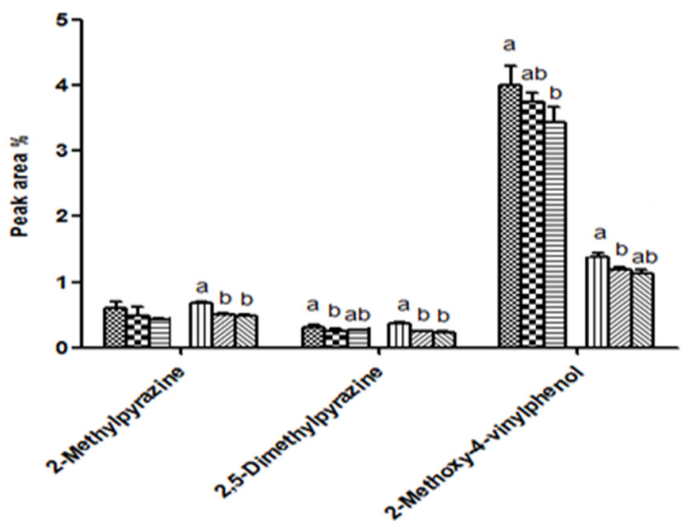

(c)

Figure 1. Levels of volatile compounds in coffee according to (a) roasting time and temperature (E$4(\mathbf{W})$ and $\mathrm{C}-4(\mathbf{W})$ : roasted at $235^{\circ} \mathrm{C}$ for $13 \mathrm{~min}$; E-13 ( $\left.\mathbf{W}\right)$ and $\mathrm{C}-13(\boldsymbol{W M})$ : roasted at $240^{\circ} \mathrm{C}$ for

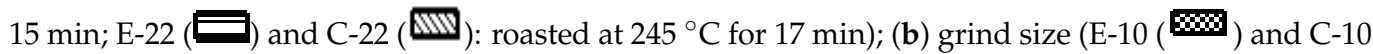
(

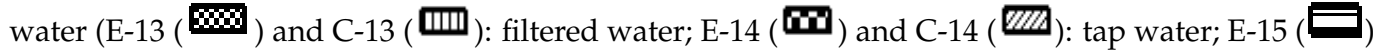
and C-15 (

\subsection{Principal Component Analysis (PCA) for Volatile Compounds in a Coffee Model System}

It is difficult to determine the difference in the mean of the volatile compounds produced by roasting and extraction methods because of the complex dynamics of the system. PCA is an effective mathematical method to reduce the dimensions of multivariate data [30]. The character with a number on the PCA biplot represents the volatile compounds defined in Table 1. PCA can identify where coffee samples made under different conditions, such as roasting conditions, grind coffee bean size, brewing methods, and types of water, are located on a volatile compounds data map [31]. 
Figure 2a shows the PCA results explaining the relative location of volatile compounds in espresso coffee. The PCA biplot explains approximately $79.75 \%$ of the variability. PC1 explains $52.81 \%$ of the total variability as the primary axis, and PC2 explains $26.95 \%$ of the entire variability as the vertical axis. One of the drawbacks of a PCA biplot is that it only explains a certain percentage of the total variability; that is, not all of the dataset is reflected in the PCA biplot [32]. Espresso coffees E-1 to E-9 (roasted at $235^{\circ} \mathrm{C}$ for $13 \mathrm{~min}$ ) were located in the second quadrant. The first group consisted of E-2 and E-3, which contained high amounts of 2-ethyl-5-methylpyrazine, 2,2'-bifuran, furfural, 5-methylfurfural, and 2-methoxy-4-vinylphenol (a8, b2, b8, b9, d3). E-10 to E-27 (coffee roasted at $240{ }^{\circ} \mathrm{C}$ for $15 \mathrm{~min}$ and $245^{\circ} \mathrm{C}$ for $17 \mathrm{~min}$ ) were located in the negative PC2. The second group consisted of E-19, E-20, and E-21, associated with high levels of 2,2'-methylene-bis-furan, 2,2'-[oxybis(methylene)]bis-furan, 1-methylpyrrole, guaiacol, and 4-ethylguaiacol (b3, b4, $\mathrm{c} 1 \mathrm{~d} 1, \mathrm{~d} 2)$. The 355- $\mu \mathrm{m}$ (E-1 to E-3, E-10 to E-12, and E-19 to E-21) and 710- $\mu \mathrm{m}$ grind sizes (E-7 to E-9, E-16 to E-18, E-25 to E-27) were located in positive $\mathrm{PC} 1$ and negative $\mathrm{PC} 1$, respectively.

Figure $2 \mathrm{~b}$ shows the PCA results and describes the relative location of volatile compounds in cold brew coffee. The PCA biplot explains about $78.82 \%$ of the variability. Most of the variability, 51.63\%, was attributed to PC1, with PC2 (the vertical axis) accounting for just $27.19 \%$ of the total variability. Cold brew coffees C-2 to C-9, which were roasted at $235^{\circ} \mathrm{C}$ for $13 \mathrm{~min}$, were located in the fourth quadrant. The first group included C-2 and C-4, with high levels of 2,6-diethylpyrazine, furfural, 5-methylfurfural, and 2-methoxy-4-vinylphenol (a6, b8, b9, d3). The second group consisted of C-14 to C-27, which contained high levels of 2,2'-methylene-bis-furan, 2,2'-[oxybis(methylene)]bis-furan, guaiacol, 4-ethylguaiacol, and 1-methylpyrrole (b3, b4, c1, d1, d2).

Figure 2 shows the PCA results and explains the relative location of volatile compounds in espresso and cold brew coffee roasted at $240^{\circ} \mathrm{C}$ for $15 \mathrm{~min}$. Together, $\mathrm{PCI}(60.62 \%)$ and PC2 (15.53\%) describe $76.14 \%$ of the total variability. Espresso coffees (E-10 to E-18) had positive PC2 scores. Cold brew coffees (C-10 to C-18) had negative PC2 scores. Espresso coffee contained high levels of 2,3-dimethylpyrazine, 2,2'-methylenebis-furan, 2,2'-[oxybis(methylene)]bis-furan, 1-furfurylpyrrole, guaiacol, 4-ethylguaiacol, and 2-methoxy-4-vinylphenol (a2, b3, b4, c2, d1, d2, d3). Conversely, cold brew contained high levels of 2-methylpyrazine, 3-ethyl-2,5-dimethylpyrazine, furfural, 5-methylfurfural, and 1-methylpyrrole (a1, a9, b8, b9, c1).

\section{Biplot (axes F1 and F2: $79.75 \%$ )}

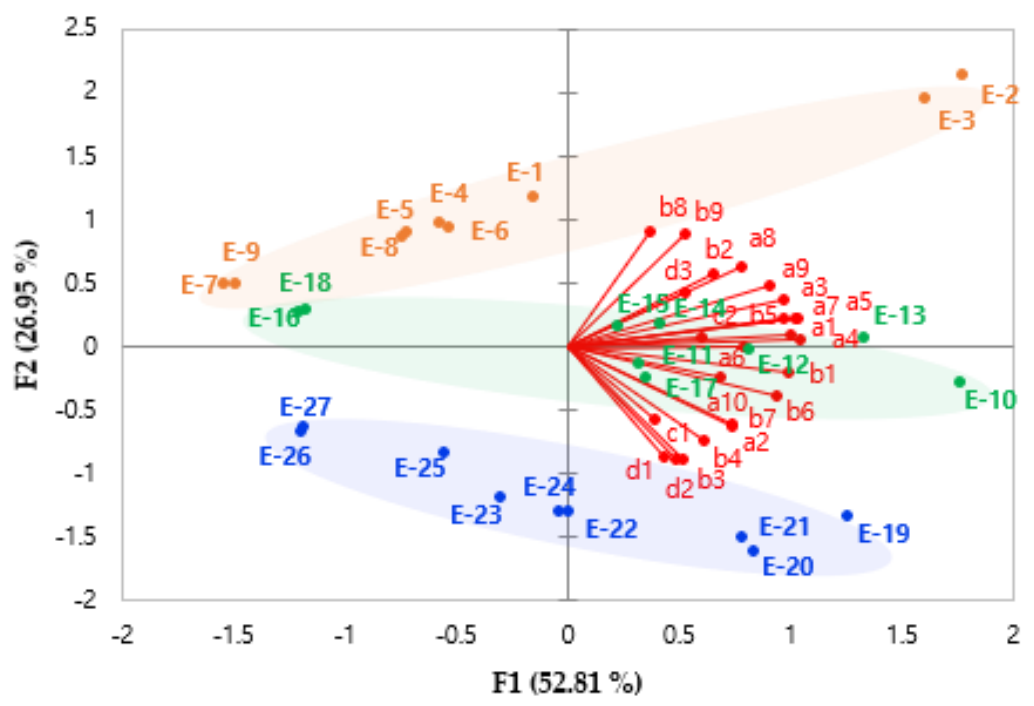

(a)

Figure 2. Cont. 
Biplot (axes F1 and F2: $78.82 \%$ )

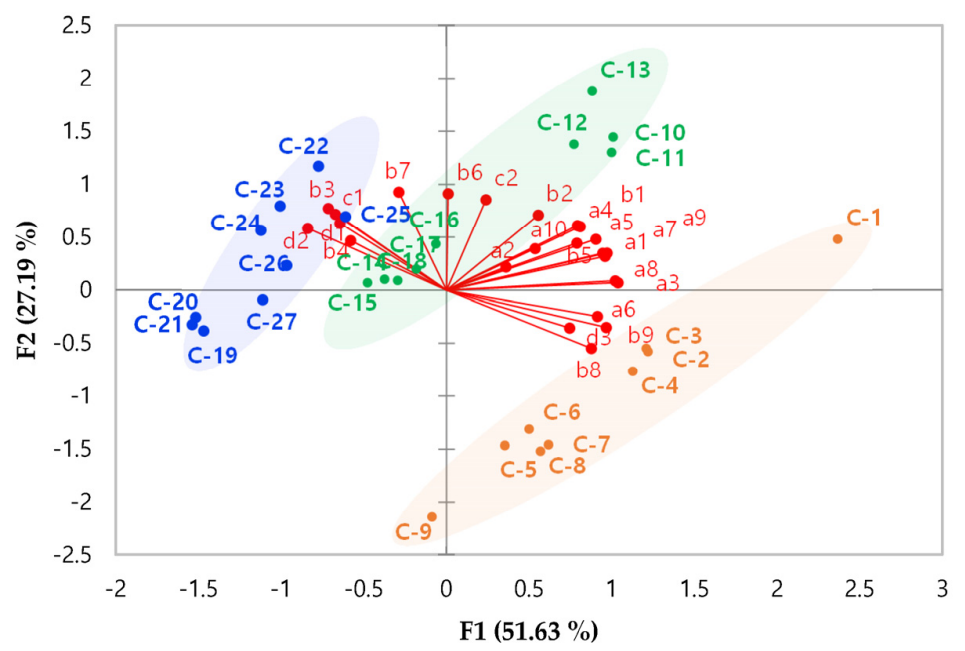

(b)

Figure 2. Principal component analysis (PCA) biplot of volatile compounds (a) in espresso coffee, (b) cold brew coffee. The relative location of volatile compounds in espresso and cold brew coffee roasted at $240{ }^{\circ} \mathrm{C}$ for $15 \mathrm{~min}$. (a1: 2-methylpyrazine, a2: 2,3-dimethylpyrazine, a3: 2,5-dimethylpyrazine, a4: 2,6-dimethylpyrazine, a5: 2-ethylpyrazine, a6: 2,6-diethylpyrazine, a7: 2-ethyl-3-methylpyrazine, a8: 2-ethyl-5-methylpyrazine, a9: 3-ethyl-2,5-dimethylpyrazine, a10: isopropenyl pyrazine, b1: 2-acetylfuran, b2: 2,2'-bifuran, b3: 2,2'-methylenebisfuran, b4: 2,2'-[oxybis(methylene)]bisfuran, b5: furfuryl alcohol, b6: furfuryl acetate, b7: furfuryl propionate, b8: furfural, b9: 5-methylfurfural, c1: 1-methylpyrrole, c2: 1-furfurylpyrrole, d1: guaiacol, d2: 4-ethylguaiacol, d3: 2-methoxy-4-vinylphenol.). E and C mean extraction method of expresso and cold brew, respectively. According to the roasting conditions, sample numbers were divided into 1 to $9\left(235^{\circ} \mathrm{C}\right.$ for $\left.13 \mathrm{~min}\right), 10-18$ (240 ${ }^{\circ} \mathrm{C}$ for $\left.15 \mathrm{~min}\right)$, and $19-27$ ( $245{ }^{\circ} \mathrm{C}$ for $17 \mathrm{~min}$ ). The sample number was also assigned to the particle size of grounded coffee (355 $\mu \mathrm{m}: 1-3,10-12,19-21 ; 500 \mu \mathrm{m}: 4-6,13-15,22-24 ; 710 \mu \mathrm{m}: 7-9,16-18,25-27)$. The sample number assigned according to the size of the coffee bean was divided into three equal parts according to the type of water (filtered water: 1, 4, 7, 10,13,16, 19, 22, 25; tap water: 2, 5, 8, 11, 14, 17, 20, 23, 26; bottled water: $3,6,9,12,15,18,21,24,27)$.

\section{Discussion}

In this study, the higher the roasting temperature and the longer the roasting time, the higher the concentrations of 2,2'-methylene-bis-furan, guaiacol, and 4-ethylguaiacol and the lower the concentration of furfural. Volatile compounds from green coffee beans were reduced as the intensity of the roasting conditions increased. On the contrary, aroma chemicals produced by the Maillard reaction were increased under higher roasting conditions than mild roasting conditions. The smaller the grind size, the higher the concentration of volatile compounds. As the grind size decreases, the solid-liquid interfacial area increases, in turn, increasing the amount of volatiles that can be extracted. Types of water with different ions can have an impact on the flavor and aroma of coffee. 2-Methylpyrazine, 1-methylpyrrole, and 2-acetylfuran were the most abundant components in the cold brew coffee. Overall, the roasting conditions and extraction methods were determined to be significant factors for volatile compounds in coffee.

Author Contributions: Conceptualization, K.-G.L. and J.-M.Y.; methodology, J.-M.Y. and H.P.; software, H.P.; validation, M.C. and H.P.; formal analysis, J.-M.Y. and J.P.; investigation, J.-M.Y.; resources, M.C.; data curation, J.-M.Y.; writing—original draft preparation, J.-M.Y.; writing-review and editing, J.-M.Y.; visualization, J.P.; supervision, K.-G.L.; project administration, K.-G.L.; funding acquisition, K.-G.L. All authors have read and agreed to the published version of the manuscript. 
Funding: This research was supported by the Basic Science Research Program through the National Research Foundation of Korea [NRF, 2021R1A2B5B01002296].

Acknowledgments: The authors would like to thank the support of Dongguk University.

Conflicts of Interest: The authors declare that there is no conflict of interest.

\section{References}

1. Simões, J.; Maricato, É.; Nunes, F.M.; Domingues, M.R.; Coimbra, M.A. Thermal stability of spent coffee ground polysaccharides: Galactomannans and arabinogalactans. Carbohydr. Polym. 2014, 101, 256-264. [CrossRef]

2. Albouchi, A.; Murkovic, M. Formation kinetics of furfuryl alcohol in a coffee model system. Food Chem. 2018, 243, 91-95. [CrossRef] [PubMed]

3. Moon, J.-K.; Shibamoto, T. Role of Roasting Conditions in the Profile of Volatile Flavor Chemicals Formed from Coffee Beans. J. Agric. Food Chem. 2009, 57, 5823-5831. [CrossRef]

4. Herawati, D.; Giriwono, P.E.; Dewi, F.N.A.; Kashiwagi, T.; Andarwulan, N. Critical roasting level determines bioactive content and antioxidant activity of Robusta coffee beans. Food Sci. Biotechnol. 2019, 28, 7-14. [CrossRef]

5. Seok, Y.-J.; Lee, K.-G. Analysis of furan in semi-solid and paste type foods. Food Sci. Biotechnol. 2020, 29, 293-301. [CrossRef] [PubMed]

6. Lee, S.J.; Kim, M.K.; Lee, K.-G. Effect of reversed coffee grinding and roasting process on physicochemical properties including volatile compound profiles. Innov. Food Sci. Emerg. Technol. 2017, 44, 97-102. [CrossRef]

7. Severini, C.; Derossi, A.; Ricci, I.; Fiore, A.G.; Caporizzi, R. How Much Caffeine in Coffee Cup? Effects of Processing Operations, Extraction Methods and Variables; Intechopen: London, UK, 2017; Volume 69002, pp. 45-85.

8. Park, S.-H.; Jo, A.; Lee, K.-G. Effect of various roasting, extraction and drinking conditions on furan and 5-hydroxymethylfurfural levels in coffee. Food Chem. 2021, 358, 129806. [CrossRef]

9. Kwon, J.; Ahn, H.; Lee, K.-G. Analysis of $\alpha$-dicarbonyl compounds in coffee (Coffea arabica) prepared under various roasting and brewing methods. Food Chem. 2021, 343, 128525. [CrossRef]

10. Cameron, M.I.; Morisco, D.; Hofstetter, D.; Uman, E.; Wilkinson, J.; Kennedy, Z.; Fontenot, S.A.; Lee, W.; Hendon, C.H.; Foster, J.M. Systematically Improving Espresso: Insights from Mathematical Modeling and Experiment. Matter 2020, 2, 631-648. [CrossRef]

11. Severini, C.; Ricci, I.; Marone, M.; DeRossi, A.; De Pilli, T. Changes in the Aromatic Profile of Espresso Coffee as a Function of the Grinding Grade and Extraction Time: A Study by the Electronic Nose System. J. Agric. Food Chem. 2015, 63, $2321-2327$. [CrossRef] [PubMed]

12. Navarini, L.; Rivetti, D. Water quality for Espresso coffee. Food Chem. 2010, 122, 424-428. [CrossRef]

13. Cammenga, H.; Zielasko, B. Kinetics and development of boiler scale formation in commercial coffee brewing machines. In Proceedings of the COLLOQUE Scientifique International sur le Café, Nairobi, Kenya, 20-25 July 1997.

14. Dórea, J.G.; da Costa, T.H.M. Is coffee a functional food? Br. J. Nutr. 2005, 93, 773-782. [CrossRef]

15. Petracco, M. Technology IV: Beverage Preparation: Brewing Trends for the New Millennium. In COFFEE Recent Developments; Blackwell Science Ltd.: London, UK, 2001.

16. Andueza, S.; De Peña, M.-P.; Cid, C. Chemical and Sensorial Characteristics of Espresso Coffee as Affected by Grinding and Torrefacto Roast. J. Agric. Food Chem. 2003, 51, 7034-7039. [CrossRef] [PubMed]

17. Salamanca, C.A.; Fiol, N.; González, C.; Saez, M.; Villaescusa, I. Extraction of espresso coffee by using gradient of temperature. Effect on physicochemical and sensorial characteristics of espresso. Food Chem. 2017, 214, 622-630. [CrossRef] [PubMed]

18. Andueza, S.; Maeztu, L.; Pascual, L.; Ibáñez, C.; De Peña, M.-P.; Cid, C. Influence of extraction temperature on the final quality of espresso coffee. J. Sci. Food Agric. 2003, 83, 240-248. [CrossRef]

19. Angeloni, G.; Guerrini, L.; Masella, P.; Innocenti, M.; Bellumori, M.; Parenti, A. Characterization and comparison of cold brew and cold drip coffee extraction methods. J. Sci. Food Agric. 2018, 99, 391-399. [CrossRef]

20. Perez, M. Cold Brew might Save the Coffee Market. Available online: https://www.bloomberg.com/news/articles/2017-07-19 / hot-sales-of-cold-brew-might-just-be-what-coffee-market-needs (accessed on 2 February 2021).

21. Fuller, M.; Rao, N.Z. The Effect of Time, Roasting Temperature, and Grind Size on Caffeine and Chlorogenic Acid Concentrations in Cold Brew Coffee. Sci. Rep. 2017, 7, 16206. [CrossRef]

22. Shin, K.-S. The Chemical Characteristics and Immune-Modulating Activity of Polysaccharides Isolated from Cold-Brew Coffee. Prev. Nutr. Food Sci. 2017, 22, 100-106.

23. Burdock, G.A. Fenaroli's Handbook of Flavor Ingredients; CRC Press: Boca Raton, FL, USA, 2016.

24. Flament, I. Coffee Flavor Chemistry; John Wiley \& Sons: Hoboken, NJ, USA, 2001.

25. Mottram, D.S. The Maillard Reaction: Source of Flavour in Thermally Processed Foods. In Flavours and Fragrances; Springer: Berlin/Heidelberg, Germany, 2007; pp. 269-283.

26. Sekiwa, Y.; Kubota, K.; Kobayashi, A. Characteristic Flavor Components in the Brew of Cooked Clam (Meretrix lusoria) and the Effect of Storage on Flavor Formation. J. Agric. Food Chem. 1997, 45, 826-830. [CrossRef]

27. Vorotnikov, V.; Mpourmpakis, G.; Vlachos, D.G. DFT Study of Furfural Conversion to Furan, Furfuryl Alcohol, and 2-Methylfuran on Pd(111). ACS Catal. 2012, 2, 2496-2504. [CrossRef]

28. Bhumiratana, N.; Adhikari, K.; Chambers, E. Evolution of sensory aroma attributes from coffee beans to brewed coffee. LWT 2011, 44, 2185-2192. [CrossRef] 
29. Derossi, A.; Ricci, I.; Caporizzi, R.; Fiore, A.; Severini, C. How grinding level and brewing method (Espresso, American, Turkish) could affect the antioxidant activity and bioactive compounds in a coffee cup. J. Sci. Food Agric. 2018, 98, 3198-3207. [CrossRef] [PubMed]

30. Jeong, D.-W.; Heo, S.; Lee, B.; Lee, H.; Jeong, K.; Her, J.-Y.; Lee, K.-G.; Lee, J.-H. Effects of the predominant bacteria from meju and doenjang on the production of volatile compounds during soybean fermentation. Int. J. Food Microbiol. 2017, 262, 8-13. [CrossRef]

31. Lee, H.J.; Cho, I.H.; Lee, K.E.; Kim, Y.-S. The Compositions of Volatiles and Aroma-Active Compounds in Dried Omija Fruits (Schisandra chinensis Baillon) According to the Cultivation Areas. J. Agric. Food Chem. 2011, 59, 8338-8346. [CrossRef] [PubMed]

32. Kim, M.K.; Kim, M.-Y.; Lee, K.-G. Categorization of fruits according to their content of polyphenols and vitamin C, antiradical activity, and quality parameters. J. Food Process. Preserv. 2017, 42, e13421. [CrossRef] 